\title{
The effect of interferon-beta on oxidative stress in patients with multiple sclerosis
}

\author{
Kassim S. Abdullah \\ Department of Pharmacology, College of Medicine, University of Mosul, Mosul, Iraq. \\ Correspondence: Kassim S. Abdullah. abdullahkassim@yahoo.com.
}

(Ann Coll Med Mosul 2018; 40 (2): 18-23).

Received: 10 ${ }^{\text {th }}$ Jun. 2013; Accepted: $22^{\text {nd }}$ Dec. 2013.

\begin{abstract}
Objective: To assess the effect of interferon-beta on oxidative stress and total antioxidant status in patients with multiple sclerosis (MS).

Design: Case-control study.

Setting: College of Medicine and Ibn-Sina Teaching Hospital, Mosul.

Methodology: The study included 40 female patients with MS. They divided into 2 groups of 20 patients each. Group one included newly diagnosed MS patients and group 2 with relapsing-remitting multiple sclerosis (RRMS) in remission phase, who were on interferon therapy. Another twenty apparently healthy females, age matched with the patients, were considered as a control. Malondyaldehyde (MDA) and total antioxidant status (TAS) were measured in all groups.

Results: MDA values of both patients groups $(1.48 \pm 0.59 \mu \mathrm{mol} / \mathrm{l}$ and $1.00 \pm 0.49 \mu \mathrm{mol} / \mathrm{l}$, respectively), were significantly higher than those of the control group $(0.60 \pm 0.18 \mu \mathrm{mol} / \mathrm{l})(\mathrm{p}<0.001)$. MDA values were significantly higher in newly diagnosed group than of RRMS 0.001). The TAS values of both patients groups $(0.91 \pm 0.26 \mathrm{mmol} / \mathrm{l}$ and $1.43 \pm 0.20 \mathrm{mmol} / \mathrm{l}$, respectively) were significantly lower than those of the control group $(2.14 \pm 0.21 \mathrm{mmol} / \mathrm{l}),(p<0.001)$. TAS values of the newly diagnosed patients were significantly lower than those of the patients group with RRMS on interferon thera patients group $(p<0.001)$.

Conclusion: MS patients have higher levels of MDA and lower levels of TAS than the control group. The newly diagnosed patients have significantly higher levels of MDA and lower TAS than RRMS patients on interferon-beta therapy. This result may give a new insight about interferon being effective in management of MS by acting as antioxidant.
\end{abstract}

Keywords: Multiple Sclerosis, Oxidative Stress, Interferon-Beta.

\section{تأثير إنترفيرون- بيتا على حالة الإجهاد التأكسدي في مرضى تصلب الأعصاب المتعدد}

$$
\text { فرع الأدوية، كلية الطب، جامعة المبوصل، الموصل، العراق }
$$

الخلاصة

الهـف: لتقييم تأثير إنترفيرون- بيتا على حالة الإجهاد التاكسدي وحالة مضادات الأكسدة لمرضى تصلب الأعصاب المتعدد.

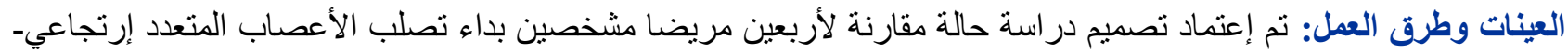

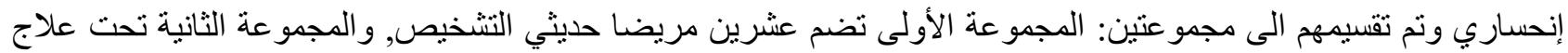
إنترفيرون- بيتا في حالة الإنحسار, ومجمو عة أخرى تضم عشرين من الأصحاء كمجمو عة سيطرة، شملتهم الدراسة. لكل شخص من مجمو عتي المرضى و السيطرة تم قياس مستوى المالونديهايد, حالة مضاد فئن الادات الأكسدة الكلية.

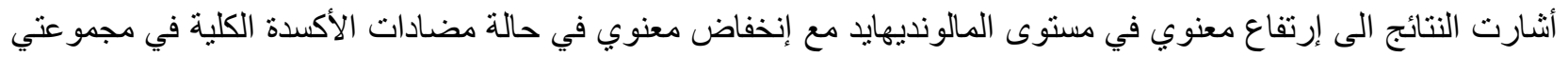

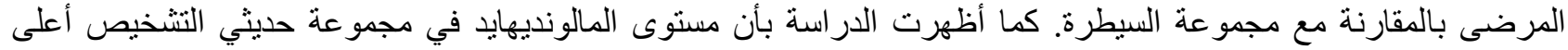
معنويا وحالة مضادات الأكسدة الكلية أقل معنويا من مجموعة كمة تصلب الأبرة العصاب المتعدد إرتجاعي-إنحساري تحت علاج الإنترفيرون-بيتا. 


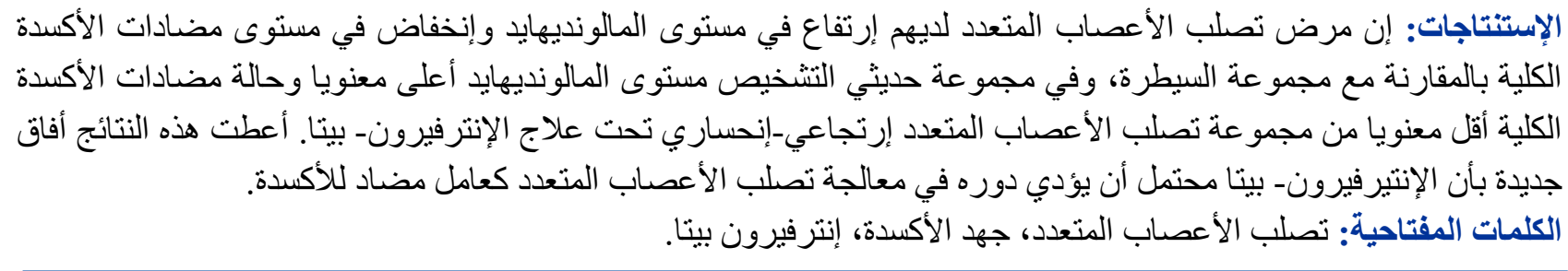

\section{INTRODUCTION}

$\mathrm{M}$ ultiple sclerosis (MS) is a chronic, autoimmune disease of the central nervous system (CNS), characterized by inflammation, demyelination, oligodendrocyte loss, axonal injury and oxidative stress. ${ }^{1}$ It affects the myelin sheath, ${ }^{2}$ the fatty tissue that surrounds the nerve fibers protecting and allowing them to conduct electrical impulses. $^{3} \quad$ Although the reasons for the autoimmune demyelinization are not clear, ${ }^{4}$ one of these reasons is the neuronal imbalance between oxidants and antioxidants products in favor of the former. $^{5}$

Prevalence of MS worldwide is estimated at one million cases; in the United States (US) it is 250,000- 350,000. Although not generally considered life threatening, this disease attributes in about 3,000 deaths each year in the US. ${ }^{6}$

Oxidative stress is defined in general as excess formation and/or insufficient removal of highly reactive molecules such as reactive oxygen species (ROS). ${ }^{7}$ In the absence of adequate antioxidant defenses, ROS can cause oxidative damage to macromolecules resulting in oxidation of lipids, proteins and deoxyribonucleic acid (DNA). ${ }^{8}$

Central nervous system is susceptible to ROSinduced damage, because the brain consumption of oxygen is high, and the concentration of endogenous antioxidants is low. ${ }^{9}$ Great number of evidences indicate that oxidative stress plays a major role in the pathogenesis of MS.,10

Mitochondrial proteins and DNA are highly vulnerable to oxidative damage, ${ }^{11}$ and therefore it is expected that free radical-mediated mechanisms may cause mitochondrial injury in MS. ${ }^{12-15}$ The exact mechanisms responsible for increased oxidative stress in MS patients need further exploration. $^{16}$

Immunomodulatory therapies have shown to reduce the rate of relapse significantly, and delay the progression of neurological disability in patients with relapsing-remitting multiple sclerosis
(RRMS). ${ }^{17}$ Interferons are considered to be members of the cytokine family of proteins, ${ }^{18}$ interferon beta (IFN- $\beta$ ) is a first line treatment for (MS), ${ }^{19}$ and as key component of the innate immune system. $^{18}$ It can cause complex immunomodulatory effects, but its mechanism of action as an immuno-modulator in the treatment of multiple sclerosis is not fully understood. ${ }^{18,20}$ IFN- $\beta$ has been shown to inhibit endothelial nitric oxide synthetase (NOS) activity and suppress endogenous nitric oxide (NO) free radical production. $^{21}$

The present study aimed to assess the effect of IFN- $\beta$ on oxidative stress and total antioxidant status in patients with (MS).

\section{SUBJECTS AND METHODS}

The study had approval from College of medicine, University Mosul. Forty female patients with MS (according to Mc Donald criteria), with age range between 25 \& 45 years, were divided into 2 groups of twenty patients each. Group one included newly diagnosed MS patients and group 2 included patients with RRMS in remission phase on interferon therapy. The patients were registered in the Neurology Outpatient Department at Ibn Sina Teaching Hospital. Another twenty apparently healthy females, age matched with the patients, were considered as a control.

Pregnant and lactating women, individuals receiving trace elements, antioxidants or vitamin $B$ complex, patients with acute or chronic illness other than MS, smokers and alcohol users were excluded from the study.

The studied groups were subjected to measurement of weight and height to derive body mass index (BMI), according to the equation:

$\mathrm{BMl}=$ weight $(\mathrm{kg}) /$ height $(\mathrm{m}) .{ }^{22}$ Expanded Disability Status Score (EDSS) was assessed in MS patients group.

Serum MDA level, which is the consequence of lipid peroxidation and a marker of oxidative stress 
was measured using thiobarbiturc acid (TBA) assay. ${ }^{23}$ TAS was measured using Randox TAS kit (London-UK) following the instructions included in the leaflet of the kit. ${ }^{24}$

\section{Statistical Analysis}

Computer feeding was conducted by prepared computer program SPSS version 18. ANOVA Test (Analysis Of Variance) was used to identify the variation in the different variables. All values expressed as Mean \pm SD and $P$ value of $<0.05$ was considered to be statistically significant. ${ }^{25}$

\section{RESULTS}

The individuals in the MS and control groups were comparable in terms of age and BMI as shown by non statistically significant differences between the groups ( $p>0.5)$, Table 1 .

Table 2 shows the comparison of MDA and TAS in the studied groups. MDA values of both patients group were higher than those of the control group $(p<0.001)$, and MDA values were higher in newly diagnosed patient group than those of RRMS patients group on interferon therapy $(p<0.001)$.

TAS values of both patients groups were significantly lower than those of the control group $(p<0.001)$, and TAS values of the newly diagnosed patients group were significantly lower than those of the patients group with RRMS on interferon therapy $(p<0.001)$. EDSS was higher in newly diagnosed patients group than patients group who is on interferon therapy $(p<0.001)$.

Table 1. The age and BMI among studied groups.

\begin{tabular}{|c|c|c|c|c|}
\hline \multirow{2}{*}{ 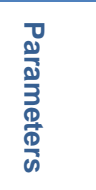 } & \multicolumn{3}{|c|}{ Mean \pm SD } & \multirow[b]{2}{*}{ 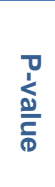 } \\
\hline & $\begin{array}{l}\text { The newly } \\
\text { diagnosed } \\
(n=20)\end{array}$ & $\begin{array}{c}\text { The RRMS } \\
\text { on IFN- } \beta \\
(n=20)\end{array}$ & $\begin{array}{l}\text { Control } \\
(\mathrm{n}=20)\end{array}$ & \\
\hline $\begin{array}{l}\text { Age } \\
\text { (years) }\end{array}$ & $35.35 \pm 8.22$ & $34.90 \pm 8.03$ & $34.55 \pm 6.19$ & NS \\
\hline $\begin{array}{l}\text { BMI } \\
(\mathrm{kg} / \mathrm{m})\end{array}$ & $25.85 \pm 4.99$ & $24.88 \pm 3.54$ & $25.39 \pm 4.69$ & NS \\
\hline
\end{tabular}

Table 2. The serum level of MDA and TAS of MS patients and control groups, and EDSS in newly diagnosed and patients on interferon therapy.

\begin{tabular}{lcccc}
\hline & \multicolumn{3}{c}{ Mean \pm SD } \\
\cline { 2 - 3 } \multicolumn{1}{c}{ Parameters } & $\begin{array}{c}\text { The Newly diagnosed } \\
(\mathbf{n}=\mathbf{2 0})\end{array}$ & $\begin{array}{c}\text { The RRMS on IFN- } \boldsymbol{\beta} \\
(\mathbf{n}=\mathbf{2 0})\end{array}$ & $\begin{array}{c}\text { Control } \\
(\mathbf{n}=20)\end{array}$ & P-value \\
MDA $(\mu \mathrm{mol} / \mathrm{l})$. & $1.48 \pm 0.59^{*}$ & $1.00 \pm 0.49^{*}$ & $0.60 \pm 0.18^{*}$ & $<0.0001$ \\
TAS $(\mathrm{mmol} / \mathrm{l})$ & $0.91 \pm 0.26^{*}$ & $1.43 \pm 0.20^{*}$ & $2.14 \pm 0.21^{*}$ & $<0.0001$ \\
EDSS & $3.10 \pm 1.08$ & $1.77 \pm 0.57$ & -- & $<0.0001$ \\
\hline
\end{tabular}

${ }^{*}$ is the non-homogenous group

\section{DISCUSSION}

The present study was performed to assess the oxidative stress in a newly diagnosed relapsingremitting multiple sclerosis (RRMS) patients and in those who are in remission phase, who are on interferon therapy, by measuring plasma levels of a byproduct of lipid peroxidation, i.e. malondialdehyde (MDA), and the plasma antioxidant capacity, by measuring total antioxidant status (TAS) and in parallel way to assess the effect of interferon-beta (IFN- $\beta$ ) on the oxidant/ antioxidant status and its effect on the course of the disease using Expanded Disabling Status Score (EDSS).

The current study included 40 females divided into 2 equal groups. The groups were matched concerning the number and their ages as well as body mass index (BMI) as confirmed statistically by the absence of significant differences between the studied groups. This matching of individual group's number, age and BMI may exclude any effect of these parameters on the results of the study. The removal of the age and BMI factors interference with results of clinical trials were done in the majority of other trials concerning antioxidant field. $^{26-29}$

In this study serum MDA levels were found to be significantly higher in patients with MS of both groups compared to the healthy control subjects.

Increased MDA level in our patients, which is the consequence of lipid peroxidation and a marker of oxidative stress is an evidence of exaggerated oxidative stress in these patients. Several studies have demonstrated an increase in the levels of lipid peroxidation, evaluated by its measurement in plasma, serum and in cerebrospinal fluid (CSF) of 
MS patients with respect to healthy subjects. ${ }^{27,30-31}$ Miller et $a l^{29}$ found that MDA levels were significantly higher in serum of MS patients than the control group. Karg et $a l^{21}$ and Vinychuk et $a l^{32}$ reported that the plasma lipid peroxides levels were increased followed by decreased vitamin $E$ level in MS patients. These results are comparable to the results of this study.

Measuring TAS is better than measuring individual antioxidant enzymes, because TAS gives a more precise indication of the relationship between antioxidants and disease. ${ }^{3}$ In this study TAS concentration was lower in MS patients of both groups, than that of the control group. This result is in accordance with the results of previous studies that compared the concentrations of TAS and individual antioxidant enzymes in MS patients. $^{3,29,33-34}$ Choi et $a l^{35}$ reported that glutathione (GSH) levels were lower in patients with MS, while Miller et $a l^{36}$ found a low level of superoxide dismutase (SOD) in patients with MS. Jimenez-Jimenez et $\mathrm{al}^{26}{ }^{26}$ Besler et $\mathrm{al},{ }^{27}$ and Salemi et $a{ }^{\beta 7}$ compared the serum levels of vitamin $E$ in patients with MS and matched controls. They found that the serum level of vitamin $E$ was significantly lower in patients with MS than controls $(P<0.05)$. The decrease of the concentration of vitamin $E$, the major lipophilic chain-breaking antioxidant, confirms the possible involvement of this vitamin in MS pathogenesis. ${ }^{37}$

In this study serum MDA levels were found significantly higher in newly diagnosed patients than in RRMS. TAS levels were found to be significantly lower in newly diagnosed patients than in patients with RRMS on interferon therapy. This indicates that the oxidative stress is enhanced in non-treated patients, and lower oxidative stress in treated patients which be may attributed to the effect of IFN- $\beta$ therapy.

Koch et $a{ }^{38}$ measured blood plasma lipid peroxidation in different types of MS; they found significantly higher levels in all types compared with the control.

Oxidative stress is very high during active progression of multiple sclerosis when compared to those individuals whose multiple sclerosis is in remission or when compared with normal controls. $^{39}$ Ferretti et al, $^{40}$ report an increase in plasma lipid peroxidation in patients in an early stage of the disease.
In a follow-up study, 14 patients with RRMS were followed for 6 months with interferon-beta treatment. It was reported that erythrocyte vitamin $E$ level was reduced $(P<0.001)$ before treatment, but had regained the same level as in controls after 6 months of IFN- $\beta$ therapy. The authors concluded that interferon treatment seemed to exert a sparing effect toward the erythrocyte vitamin $\mathrm{E}$ content. ${ }^{41}$

In this study, EDSS was higher in newly diagnosed patients group than the patient group on interferon therapy $(p<0.001)$, indicating the beneficial effect of IFN- $\beta$ on the progression of the disease. Immunomodulatory therapies have shown to reduce the rate of relapse significantly, and delay the progression of neurological disability in patients with RRMS. ${ }^{17}$ Interferon-beta reduces the overall frequency of MS attacks by approximately $30 \%$ compared with placebo in therapeutic trials. ${ }^{42,43}$

One of the greater challenges facing researchers trying to explain the mechanism of action of interferon in MS is the complex pathological process in this disease. ${ }^{44}$ It is now generally agreed that initial step in MS episode is an inflammatory process initiated by activation of $T$ cells that cross blood brain-barrier (BBB) and target specific myelin antigens within CNS, the activated $T$ cells will respond by producing cytokins that will stimulate inflammatory process leading to tissue injury. ${ }^{45}$

Review of literature provides limited conflicting data concerning the mechanism of interferon-beta in the management of MS, since its exact mechanism of action is not completely understood. ${ }^{19}$ IFN- $\beta$ appears to be directly involved in increasing the expression and concentration of anti-inflammatory agents while down regulating the expression of proinflammatory cytokines. ${ }^{46}$ Therefore the proposed mechanism of action of IFN- $\beta$ in MS is immune modulation via its effects on $T$ cells, (decreasing immune cell entering across the BBB, inducing apoptosis of autoreactive $T$ cells, promoting $T$ regulatory cell activity, and inducing a shift to anti-inflammatory cytokines). ${ }^{17}$

It is well known that inflammation raises reactive oxygen species (ROS) levels leading to oxidative stress (OS). ${ }^{2}$ Excessive release of free radicals may play an important role in MS pathogenesis, ${ }^{9}$ 
and may promote transendothelial leukocyte migration and free radicals generation that contribute to oligodendrocyte damage and axonal degeneration. ${ }^{47}$ According to this information, and the results obtained in this study, a new insight may be drawn that interferon- beta may exhibit its effect in management of MS by acting as antioxidant through its anti inflammatory effect. Ongoing and future studies will increase our understanding of the actions of IFN- $\beta$ on the immune system and the CNS, which will in turn aid advances in the management of MS.

\section{CONCLUSION}

Patients with multiple sclerosis have higher levels of MDA and lower levels of TAS than the control group. This high value of MDA reflects enhancement of oxidative stress in MS patients, and low value of TAS may be due to development of oxidative stress that reduces the concentration of the antioxidant status of the body.

The newly diagnosed patients have higher levels of MDA and lower TAS than RRMS patient group. This indicates that IFN- $\beta$ in management of MS may be via its antioxidant property.

\section{REFERENCES}

1. Tasset I, Aguera E, Sanchez-Lopez F, et al Peripheral oxidative stress in relapsing-remitting multiple sclerosis. Clin biochem 2012; 45: 440- 444.

2. Gilgun-Sherki Y, Melamed E, Offen D. The role of oxidative stress in the pathogenesis of multiple sclerosis: The need for effective antioxidant therapy. J Neurol 2004; 251: 261-268.

3. Hadzovic- Dzuvo A, Lepara O, Valjevac $A$, et al Serum total antioxidant capacity in patients with multiple sclerosis. J Bosnian Bas. Med Sci 2011; 11 (1): 33-36.

4. Tavazzi B, Batocchi A B, Amorini A M. Serum Metabolic Profile in Multiple Sclerosis Patients. Mult Scle Inter 2011; Article ID 167156.

5. Acar G. Nitric oxide as an activity marker in multiple sclerosis. J Neurol 2003; 250: 588-592.

6. Kidd PM. Multiple Sclerosis, an Autoimmune Inflammatory Disease: Prospects for its Integrative Management. Alter Med Rev 2001; 6 (6).

7. Maritim AC, Sanders RA, Watkins JB. Diabetes, Oxidative Stress and Antioxidants: A review, J Biochem Mol Toxicol 2003; 17: $24-38$.

8. Griffiths H R. Biomarkers. Mol Aspects Med 2002; 23 : 101-208.

9. Miller E, Mrowicka M, Zołyński K. Oxidative stress in multiple sclerosis. Pol Merkur Lekarski 2009; 27: 499502.

10. Oliveira SR, Kallaur AP, Simao ANC, et al. Oxidative stress in multiple sclerosis patients in clinical remission: Association with the expanded disability status scale. $J$ Neurol Sci 2012; 321: 49-53.
11. Higgins GC, Beart PM, Shin YS, et al Oxidative stress: emerging mitochondrial and cellular themes and variations in neuronal injury. J Alzheimers Dis 2010; 20: S 453-473.

12. Lu F, Selak M, O'Connor J, et al Oxidative damage to mitochondrial DNA and activity of mitochondrial enzymes in chronic active lesions of multiple sclerosis. $J$ Neurol Sci 2000; 177: 95-103.

13. Kalman B, Leist TP. A mitochondrial component of neurodegeneration in multiple sclerosis. Neuromolecular Med. 2003; 3: 147-158.

14. Mao $P$, Reddy $H$. Is multiple sclerosis a mitochondrial disease? J Biochim Biophys Acta 2010; 1802: 66-79.

15. Van Horssen J, Witte ME, Schreibelt G, de Vries HE. Radical changes in multiple sclerosis pathogenesis. Biochem Biophys Acta 2011; 18 12: 141-150.

16. Uttara B, Singh AV, Zamboni P. Oxidative stress and neurodegenerative diseases: a review of upstream and downstream antioxidant therapeutic options. Curr Neuropharmacol 2009; 7(1): 65-74.

17. Tornes L, Delgado S, Garcia-Buitrago, et al Focal segmental glomerulosclerosis secondary to subcutaneous interferon $b-1 a$ treatment in a patient with multiple sclerosis. Multiple Sclerosis and Related Disorders 2012; 1: 148-151.

18. Rudick RA, Goelz SE. Beta-interferon for multiple sclerosis. J experim cel Resea 2011; 317: $130-1311$.

19. Arscott W T, Soltys J, Knight J, et al Interferon $\beta-1 b$ directly modulates human neural stem/progenitor cell fate, Brain Res 2011; $1413: 1$ - 8 .

20. Stuerzebecher $S$, Wandinger KP, Rosenwald A, et al Expression profiling identifies responder and nonresponder phenotypes to interferon-b in multiple sclerosis. J Brain 2003; 126: 1419-1429.

21. Karg E, Klivenyi P, Nemeth I, Bencsik K, Pinter S, Vecsei L. Non-enzymatic antioxidants of blood in multiple sclerosis. J Neurol 1999; 246 (7): 533-539.

22. Leemarkers EA, Dunn AL, Blair SN. Exercise management of obesity. Medical Clinic of North American 2000; 84(2): 419-425.

23. Buege JA, Aust SD. Microsomal lipid peroxidation. In: Methods in Enzymology. Biomembranes. Part C: Biological oxidations Microsomal, Cytochrome P-450, and other hemoprotein systems. Fleischer S, Packer L editors. San Francisco London 1978; 52: 302-306.

24. Miller NJ, Rice-Evan C, Davies MJ, Gopinathan V, Milner A. A novel method for measuring antioxidant capacity and its application to monitoring the antioxidant status in premature neonates. Clin Sci 1993; 84: 407412.

25. Kirkwood BR. Essential of Medical statistics $1^{\text {st }}$ ed. Blackwell Scientific publications, Oxford 1988; 43-56.

26. Jimenez-Jimenez FJ, de Bustos F, Molina JA, et al Cerebrospinal fluid levels of alpha- tocopherol in patients with multiple sclerosis. Neurosci Lett 1998; 249: 65-67.

27. Besler HT, Comoglu S, Okcu Z. Serum levels of antioxidant vitamins and lipid peroxidation in multiple sclerosis. J Nutr Neurosci 2002; 5: 215-220.

28. Besler HT, Comoglu. Lipoprotein oxidation, plasma total antioxidant capacity and homocysteine level in patients with multiple sclerosis. J Nutr Neurosci 2003; 6(3): 189-196. 
29. Miller E, Mrowicka M, Saluk-Juszczak J, et al The level of isoprostanes as a non-invasive marker for in vivo lipid peroxidation in secondary progressive multiple sclerosis. Neurochem Res 2011; 36: 1012-1016.

30. Naidoo R, Knapp ML. Studies of lipid peroxidation products in cerebrospinal fluid and serum in multiple sclerosis and other conditions. Clin Chem 1992; 38: 2449- 2454.

31. Calabrese V, Raffaele R, Cosentino E, Rizza V. Changes in cerebrospinal fluid levels of malondialdehyde and glutathione reductase activity in multiple sclerosis. J Int Clin Pharmacol Res 1994; 14: 119-123.

32. Vinychuk SM, Donchenko GV, Morosova RP, Kopchak OO, Pasechnaya EP, Silonov SB. Prooxidantantioxidant disbalance in multiple sclerosis and its role in the development of fatigue in patients. J Ukrainian Med 2004; 44: 11-12.

33. Carlson NG, Rose JW. Antioxidants in multiple sclerosis: do they have a role in therapy? CNS Drugs 2006; 6: 433-441.

34. Van Horssen J, Schreibelt G, Drexhage J, et al Severe oxidative damage in multiple sclerosis lesions coincides with enhanced antioxidant enzyme expression. Free Radic Biol Med 2008; 45 (12): 1729-1737.

35. Choi IY, Lee SP, Denney DR, Lynch SG.Lower levels of glutathione in the brains of secondary progressive multiple sclerosis patients measured by $1 \mathrm{H}$ magnetic resonance chemical shift imaging at $3 \mathrm{~T}$. J Mult Scler 2011; 17: 289-96.

36. Miller E, Mrowicka M, Malinowska K, Zolynski K, Kedziora J. Effect of the whole body cryotherapy on total antioxidative status and activities of som antioxidative enzymes in blood of patients with multiple sclerosispreliminary study. J Med Invest 2010; 57:168-73.

37. Salemi G, Gueli MC, Vitale F, et al Blood lipids, homocysteine, stress factors, and vitamins in clinically stable multiple sclerosis patients; Lipids in Health and Disease 2010; 9 (19): 1-3.
38. Koch M, Ramsaransing GS, Arutjunyan AV, et al Oxidative stress in serum and peripheral blood leukocytes in patients with different disease courses of multiple sclerosis. J Neurol 2006; 253: 483-487.

39. Levine SM. The role of reactive oxygen species in the pathogenesis of multiple sclerosis. Medical Hypotheses 1992; 39 (3): 271-274.

40. Ferretti G, Bacchetti T, Principi F. Increased levels of lipid hydroperoxides in plasma of patients with multiple sclerosis: a relationship with paraoxonase activity. Mult Scler 2005; 11: 677-682.

41. Karg E, Klivenyi P, Nemeth I, Bencsik K, Pinter S, Vecsei L. Non-enzymatic antioxidants of blood in multiple sclerosis. J Neurol 2003; 246 (7): 533-539.

42. Tomassini V, Paolillo A, Russo $P$, et al Predictors of long-term clinical response to interferon beta therapy in relapsing multiple sclerosis. J Neurol 2006; 253 : 287293

43. Carmona O, Casado V, Moral E, et al Interferon-beta 1b in Multiple Sclerosis: Effect on Progression of $\bar{D}$ isability and Clinical Markers of Treatment Response. Eurp Neurol 2008; 60: 279-284.

44. Lucas K, Arnason B. Mechanisms of Action and Clinical Effects of Beta Interferon in Multiple Sclerosis. Proceedings of the MS Forum Modern Management Workshop; 1999.

45. Stuerzebecher S, Maibauer R, Huner A, et al. Pharmacodynamic comparison of single doses of interferon beta-1a and interferon beta- $1 \mathrm{~b}$ in healthy volunteers. J Interferon Cytokine Res 1999; 19.

46. Kieseier BC. The Mechanism of Action of Interferonb in Relapsing Multiple Sclerosis. CNS Drugs 2011; 25 (6): 491-502

47. Lee D, Gold R, Linker RA. Mechanisms of Oxidative Damage in Multiple Sclerosis and Neurodegenerative Diseases: Therapeutic Modulation via Fumaric Acid Esters. J Intern Mole Sci 2012; 13, 11783-11803. 